\title{
Stress-strain response in gears tooth root due to low cycle fatigue
}

\author{
Marina Franulovic ${ }^{1, *}$, Kristina Markovic ${ }^{1}$, and Zdravko Herceg ${ }^{1}$ \\ ${ }^{1}$ University of Rijeka - Faculty of Engineering, Department of Mechanical Engineering Design, Vukovarska 58, 51000 Rijeka, Croatia
}

\begin{abstract}
Gears are mechanical components which experience high dynamic loading during their exploitation period. Therefore, their load carrying capacity together with life expectancy are often the main research interest in various studies. The research presented in this paper is focused on the materials response in spur gears tooth root, with the attention given to the repeated overloads during gears operation. In order to simulate low cycle fatigue by using numerical modeling of stress - strain relationship within material, the material model which takes into account isotropic and kinematic hardening is used here. Material response of specimens produced out of steel $42 \mathrm{CrMo} 4$ in different loading conditions is used for the calibration of material model, which is then applied to simulate damage initiation and materials stress - strain response in gears tooth root. The results show that materials response to the given loading conditions non-linearly change through the loading cycles.
\end{abstract}

\section{Introduction}

When transmitting torque, the gear teeth are dynamically loaded during mesh. Throughout the work process, the loads vary, while gears are operating at or near critical speed to operating under working conditions [1,2]. In addition to these loading, there are also other, additional excitations induced in the gearbox, which influence various stresses spectra in gears tooth root.

With regard to expected various stresses and in order to produce optimal gear design based on chosen material, numerous running tests on gear samples should be conducted to enable life expectancy evaluations $[3,4]$. Furthermore, these tests consider occurrence of final failure in gear tooth root, but not the damage nucleation and accumulation that result in crack initiation. In order to capture the material behavior during overload cycles which are expected to induce low-cycle fatigue in tooth root and thus analyse damage nucleation and accumulation, a combined elasto-plastic constitutive material model is taken into consideration here. It takes into account both isotropic and kinematic hardening effect $[5,6]$. The material model adequate to capture this effect is quite complex, thus its calibration is planned, based on the experimental results acquired through the uniaxial tests on samples produced out of the steel $42 \mathrm{CrMo} 4$, usually used in gears transmissions.

\section{Material behaviour of $42 \mathrm{CrMo} 4$ steel}

To describe the behavior of machine component's material during their operational life, it is important to understand the physical relationship among observed material properties together with stresses and strains values. Therefore, the material model appropriate for modelling material behavior under certain conditions must be chosen. A material model in which combination of elastic and plastic strains is taken into account is used in this paper to analyse material behavior. It takes into account isotropic and kinematic hardening / softening of the material as well as mean stress relaxation [5,7]. The nucleation and accumulation of damage can also be considered, based on the theories of damage mechanics [8]. The material model chosen to simulate material behaviour is considered to be time-and rate-independent and is intended for isothermal conditions. It is well known Chaboches material model, based on following considerations. Total strain is combined by the elastic and plastic part:

$$
\varepsilon=\varepsilon^{\mathrm{e}}+\varepsilon^{\mathrm{p}}
$$

The elastic strain follows the Hooke's law:

$$
\varepsilon^{\mathrm{e}}=\sigma /(1-D) E
$$

while the plastic strain is taken into account outside the plastic yield surface, combining the effects of both kinematic and isotropic hardening [8]:

$$
f=|\sigma /(1-D)-X|-R-\sigma_{\mathrm{y}}=0
$$

As a result of derivation of the yield surface, the law of isotropic hardening leads to the exponential expression which describe the maximum stresses variations during cycles, as a function of accumulated plastic strain and a rate of isotropic hardening: 


$$
\left(\sigma_{\max }-\sigma_{\max 0}\right) /\left(\sigma_{\max s}-\sigma_{\max 0}\right)=1-\exp (-2 b p)
$$

While isotropic hardening refers to the change of the yield surface, its translation is described through the kinematic hardening rule. It is covered here as a composition of three parts of Armostrong-Frederick model [5,7,9] [11-13], as Chaboche suggested:

$$
\Delta \sigma / 2=R_{\infty}+\sum_{i=1}^{3} X_{\infty}^{(i)} \tanh \left(\gamma^{(i)}\left(\Delta \varepsilon_{\mathrm{p}} / 2\right)\right)
$$

With the goal to model material behaviour, considering its elastic-plastic response in low-cycle fatigue regime, and thus taking into account both isotropic and kinematic non-linear rules, material parameters have been identified $[10,11]$. The calibration of material model was conducted to identify the material parameters, based on the material response recorded through the uniaxial tests on test specimens produced from steel $42 \mathrm{CrMo} 4$, normalized (296 HV) and hardened ( $420 \mathrm{HV}$ and $546 \mathrm{HV}$ ). The material parameters resulted from the optimization process based on developed genetic algorithm procedure are given in Table 1:

Table 1. Material parameters ( $\sigma_{\mathrm{y}}$ - yield stress, $b$ - rate of isotropic hardening, $R_{\infty}$ - limit of isotropic hardening, $\gamma^{(i)}$ -

rates of kinematic hardening, $X_{\infty}^{(i)}$ - backstresses).

\begin{tabular}{|c|l|c|c|c|}
\hline \multirow{2}{*}{ Par. } & \multirow{2}{*}{ Unit } & \multicolumn{3}{|c|}{ 42CrMo4 } \\
\cline { 3 - 5 } & & $\mathbf{2 9 6} \mathbf{H V}$ & $\mathbf{4 2 0} \mathbf{~ H V}$ & $\mathbf{5 4 6} \mathbf{~ H V}$ \\
\hline$\sigma_{\mathrm{y}}$ & $\mathrm{N} / \mathrm{mm}^{2}$ & 550 & 880 & 1070 \\
\hline$b$ & - & 3 & 2 & 3 \\
\hline$R_{\infty}$ & $\mathrm{N} / \mathrm{mm}^{2}$ & -110 & -330 & -420 \\
\hline$\gamma^{(1)}$ & - & 60 & 197 & 122 \\
\hline$\gamma^{(2)}$ & - & 243 & 187 & 574 \\
\hline$\gamma^{(3)}$ & - & 1249 & 2318 & 7431 \\
\hline$X_{\infty}^{(1)}$ & $\mathrm{N} / \mathrm{mm}^{2}$ & 169 & 134 & 464 \\
\hline$X_{\infty}^{(2)}$ & $\mathrm{N} / \mathrm{mm}^{2}$ & 117 & 179 & 225 \\
\hline$X_{\infty}^{(3)}$ & $\mathrm{N} / \mathrm{mm}^{2}$ & 86 & 119 & 105 \\
\hline
\end{tabular}

\section{Stress and strain analysis}

Using relevant information on material behavior which is described earlier in the paper, numerical model of gear tooth is developed by finite element method, where material model with identified material parameters was adopted. The gears model shown on Fig. 1 follow geometrical properties given in Table 2 .

The gear tooth is discretized by finite elements that have integrated materials' nonlinearities, modelled to follow the material behaviour defined by identified material parameters.

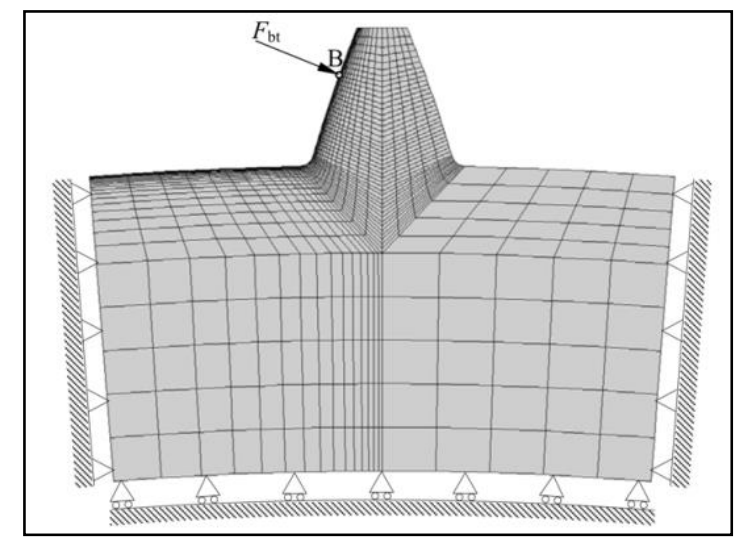

Fig. 1. Finite element model.

Table 2. Gears geometry.

\begin{tabular}{|c|c|c|}
\hline Symbol & Unit & Value \\
\hline$z_{1} / z_{2}$ & - & $21 / 124$ \\
\hline$m_{\mathrm{n}}$ & $\mathrm{mm}$ & 6 \\
\hline$\alpha_{\mathrm{n}}$ & $\circ$ & 20 \\
\hline$h_{\mathrm{a} 01}^{*}=h_{\mathrm{a} 02}^{*}$ & - & 1,25 \\
\hline$\rho_{\mathrm{a} 01}^{*}=\rho_{\mathrm{a} 02}^{*}$ & - & 0,25 \\
\hline$c_{1}^{*}=c_{2}^{*}$ & - & 0,25 \\
\hline$x_{1}=x_{2}$ & - & 0 \\
\hline$b_{1}=b_{2}$ & $\mathrm{~mm}$ & 1 \\
\hline$d_{\mathrm{a} 1} / d_{\mathrm{a} 2}$ & $\mathrm{~mm}$ & $138 / 756$ \\
\hline$\varepsilon_{\alpha}$ & - & 1,722 \\
\hline
\end{tabular}

The calculation procedure takes into account that the whole nominal transverse load in plane of action, depicted with force $F_{\mathrm{bt}}$, is applied repeatedly on the tooth flank.

The simulation was performed using high-level repeated loads acting on the characteristic outer point of single contact B, with the goal to capture low-cycle fatigue regime in the tooth root, and to analyse isotropic and kinematic hardening effect during load cycles. The stresses are expected to cause plastic strains in material both at the tooth surface and under it. Plastic, unlike elastic strains are irreversible which means that in any subsequent loading cycle, the maximum stress that material can withstand, decreases. After the removal of load, residual stress with compressive character remains in the material, under the tooth root surface [12-14].

The analyses were carried out for steel $42 \mathrm{CrMo} 4$ in normalized state with hardness of $296 \mathrm{HV}$ and for material in tempered state with hardnesses of $420 \mathrm{HV}$ and $546 \mathrm{HV}$. Results on test samples for these materials have showed that for equivalent stress values above yield limit using von Mises criteria, material is softened through the loading in both isotropic and kinematic sense. This behaviour is also expected to manifest in gears tooth root.

Figures 2,3 and 4 show values of equivalent stresses distribution through the loading cycles and also related strains for three studied materials of different hardness. Simulations were carried out for the first 50 loading 
cycles since the most changes through cycles are expected to occur in first cycles with the stabilization expectancy and refer to a critical point of transitional curve at the gears tooth root. Red full lines represent stress and black dashed lines strain. Material with 296 $\mathrm{HV}$ on Fig. 2 experiences strain in amount of 0,016 in the root when the maximum force in first cycle is applied on the tooth flank. Due to accumulation of this plastic strain in the root as it was explained before, stress is decreasing and strain is increasing to somewhat 0,03 at the end of loading cycle.

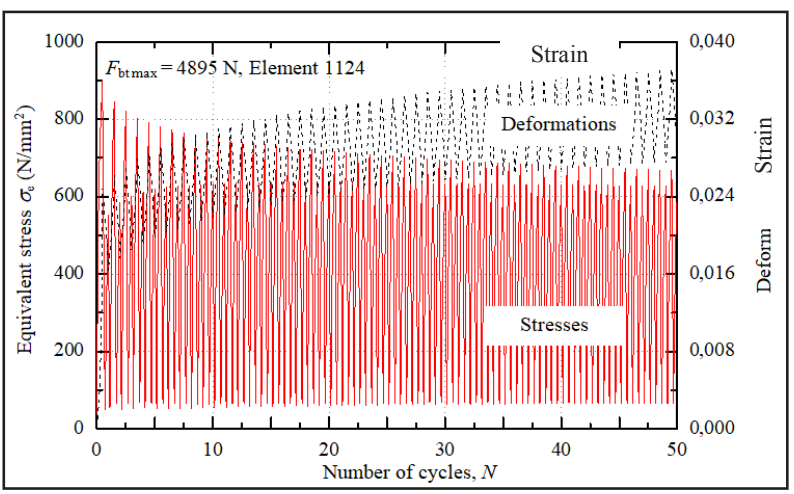

Fig. 2. Stresses and strains through cycles, $42 \mathrm{CrMo} 4-296 \mathrm{HV}$

Response of other two materials is similar to material described before but their higher value of hardness enables them to experience higher maximum stresses. Values of strain for both materials is around 0,003 and is practically not changing throughout the end of loading cycle while stresses decrease.

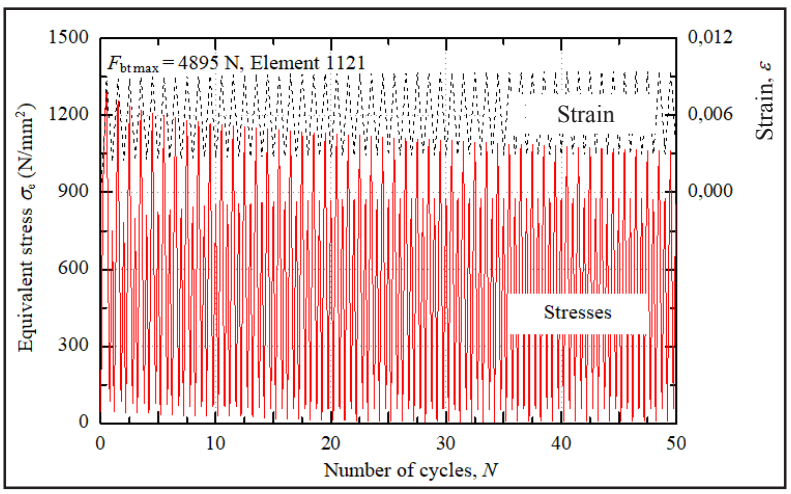

Fig. 3. Stresses and strains through cycles, $42 \mathrm{CrMo} 4-420 \mathrm{HV}$

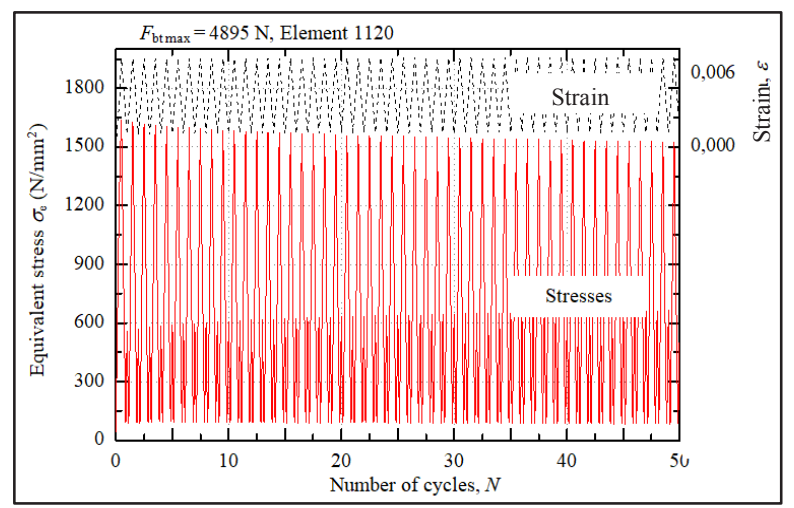

Fig. 4. Stresses and strains through cycles, $42 \mathrm{CrMo} 4-546 \mathrm{HV}$
It can be seen that close to the 50th cycle comes stabilization of strains and that it's faster for material with higher hardness values. Also, all materials show the existence of residual stress in gears tooth root after the relaxation. This is due to plastic strain below of transitional curve at the gears tooth root.

Figures 5,6 and 7 show relation between equivalent stresses and strains for a different number of cycles: the first, second, 10th, 50th and 100th. Strain ot of gears tooth is subdued to tensile stress. This loading causes plastic yielding of material below the surface. After the unloading period, regions in material that were previously deformed plastically, are now subjected to compressive stress. Although, this stress has negative value, it's curve is on positive side of diagram due to equivalent stress presentation. Hysteresis curves are somewhat above zero due to the Bauschinger effect, captured through the kinematic hardening behaviour modelling.

Hysteresis loops are created for different number of loading cycles. Loops for material 296 HV (Fig.5) have larger surface which can be explained as expected larger damage accumulation prior to crack. As tensile stress is decreasing, residual stress with compressive character is increasing to somewhat 50. cycle and then also decreases. The values of these two stresses are almost the same at 100. Cycle due to the expected stabilization.

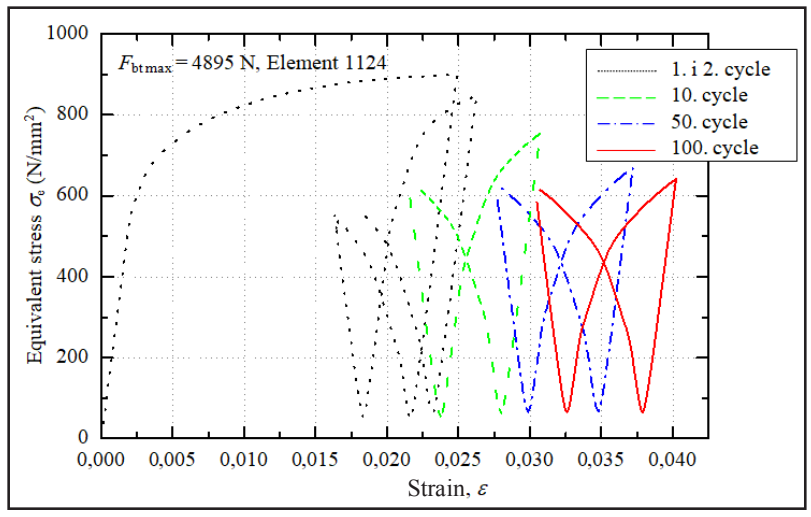

Fig. 5. Stress - strain relationship, $42 \mathrm{CrMo} 4-296 \mathrm{HV}$

Material hardened to $420 \mathrm{HV}$ (Fig.6) has its loops flatter and closer to one another and also to first relaxation hysteresis loop. This is important because it shows that this material accumulates less plastic deformation prior to crack. Also, residual stress starts to decrease around 50. cycle. This difference is biggest with material hardened to $546 \mathrm{HV}$ (Fig.7) where loops are almost overlapping and residual stress is increasing all way through the end. 


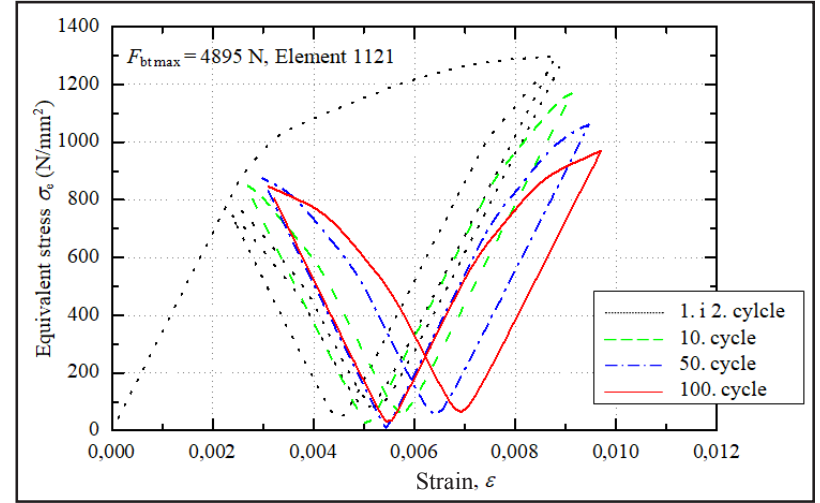

Fig. 6. Stress - strain relationship, $42 \mathrm{CrMo} 4-420 \mathrm{HV}$

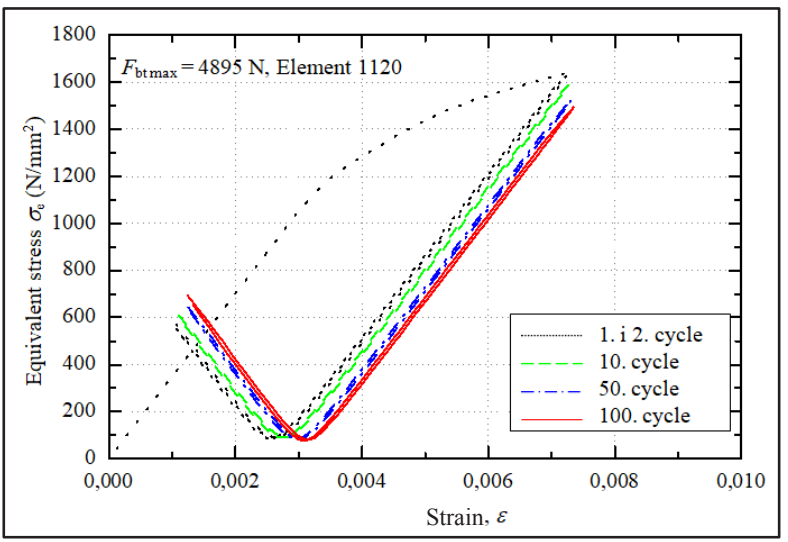

Fig. 7. Stress - strain relationship, $42 \mathrm{CrMo} 4-546 \mathrm{HV}$

Figures 8,9 and 10 show development of stress and strain components considering designated stress and strain components. Results are presented for normalized material with hardness $296 \mathrm{HV}$.

At the end, the stresses relationship considering mean stresses is given and shown in Figure 11. These results are given for 1., 2., 5., and 10. cycle. Also, calculation takes into account that value of $\sigma_{1}$ stress is highest by absolute value.

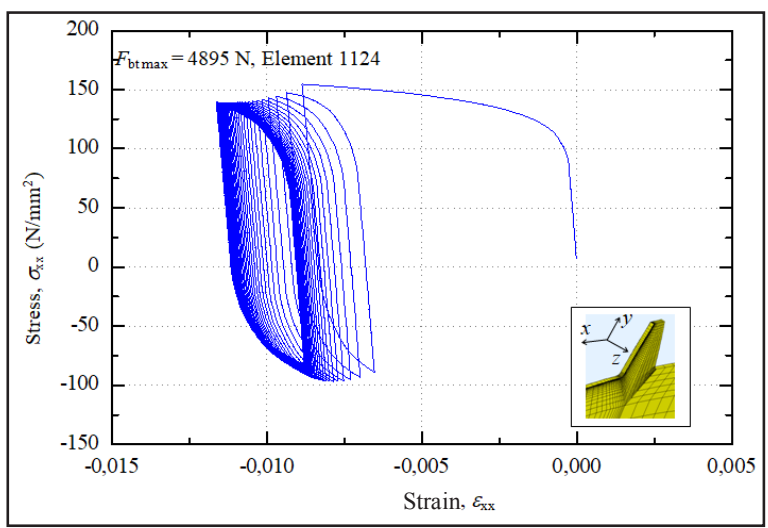

Fig. 8. Stress and strain components $\sigma_{\mathrm{xx}}$ and $\varepsilon_{\mathrm{xx}}$

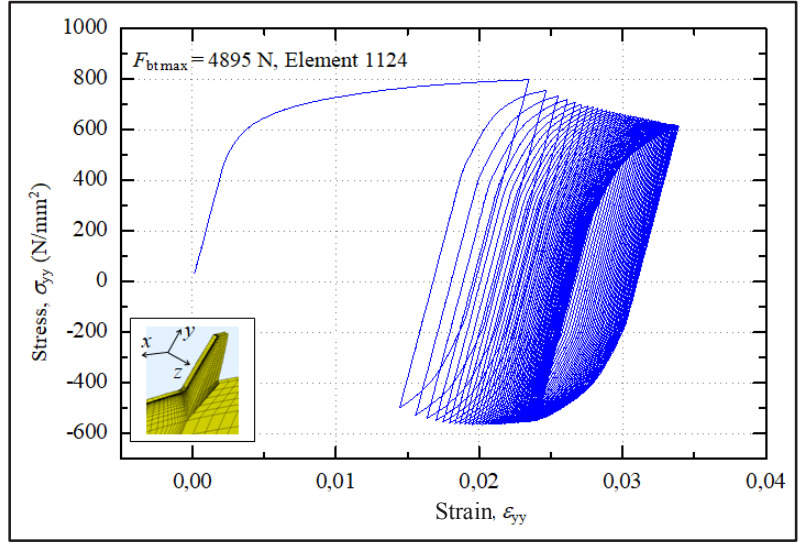

Fig. 9. Stress and strain components $\sigma_{\mathrm{yy}}$ and $\varepsilon_{\mathrm{yy}}$

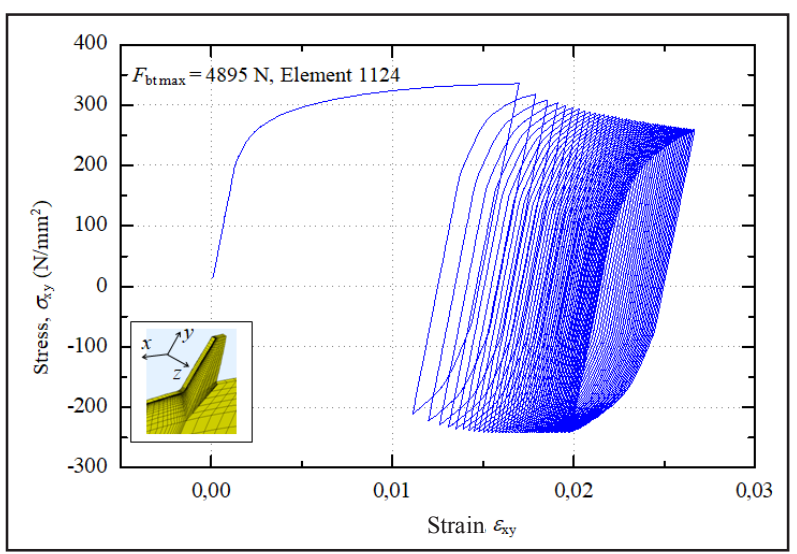

Fig. 10. Stress and strain components $\sigma_{\mathrm{xy}}$ and $\varepsilon_{\mathrm{xy}}$

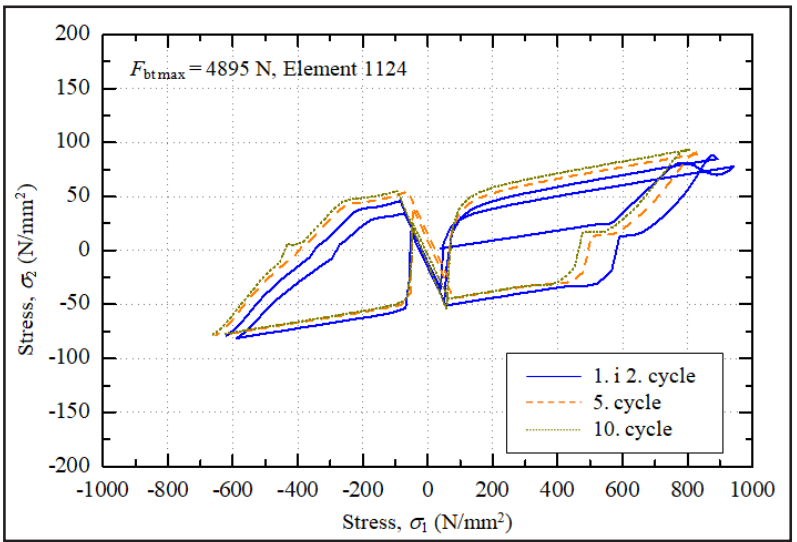

Fig. 11. Mean stresses.

Presented analyses show that softening the material in gears tooth root due to the elastic - plastic response of the material and the increase of strains in low-cycle regime has the biggest influence on material with 296 $\mathrm{HV}$, while it is reducing with the hardness increase. 


\section{Conclusion}

Previous research has been performed on the material behaviour of steel $42 \mathrm{CrMo} 4$, in normalised state with hardness $296 \mathrm{HV}$ and also in tempered state with hardnesses $420 \mathrm{HV}$ and $546 \mathrm{HV}$. The uniaxial experiments on test samples produced by them were performed to record the stress-strain response of the material to the loading signal and capture material phenomena in low-cycle fatigue regime. On the basis of data sets obtained through these procedures, material parameters have been identified with the goal to make possible the application of Chaboche's material model on modelling material behaviour of gears tooth root. Using the finite element method with elements that have adapted these material parameters, the spur involute gear tooth has been discretized. With the perspective that tooth root would have the same behavior as the test specimens used to identify parameters, the calculation of the stress and strain relationship on the tooth root loaded in tension has been conducted. The overall analysis on the stress strain response in the tooth root while overloaded by transverse load on the tooth flank has been presented through the significant load cycles. The analysis showed the importance of possibility in raising the point on the beneficial effect of plastic strains which occur bellow the tooth root surface to the decrease of tensile stresses on the tooth root in subsequent loading cycles. Also, it depends on the material properties and its influence differs for materials with the change in tempering conditions. This investigation serves as a concept and a motivation for further investigations to be made to utilize discovered favourable characteristics of residual stresses together with the softening material due to the isotropic and kinematic hardening effects on tooth root stress reduction.

\section{References}

[1] M.S. Feki, F. Chaari, M.S. Abbes, F. Viadero, A.F. del Rincon, M. Haddar, Dynamic Analysis of Planetary Gear Transmission Under Time Varying Loading Conditions, in: 2013: pp. 311318.

[2] N. Mokhtari, M. Grzeszkowski, C. Gühmann, Vibration Signal Analysis for the LifetimePrediction and Failure Detection of Future Turbofan Components, 37 (2017) 422-431.

[3] ISO 6336-6 Calculation of load capacity of spur and helical gears, 2006.

[4] D.R. McPherson, S.B. Rao, Mechanical Testing of Gears, in: Mech. Test. Eval., ASM International, 2000: pp. 861-872.

[5] J.L. Chaboche, A review of some plasticity and viscoplasticity constitutive theories, Int. J. Plast. 24 (2008) 1642-1693. doi:10.1016/j.ijplas.2008.03.009.

[6] Q. Zhu, Shun-Peng;Yue, Peng;Correia, Jose;Blason, Sergio;De Jesus, Abilio;Wang, Strain energy-based fatigue life prediction under variable amplitude loadings, Struct. Eng. Mech. 66 (2018) 151-160.

[7] S. Bari, T. Hassan, Anatomy of coupled constitutive models for ratcheting simulation, Int. J. Plast. 16 (2000) 381-409. doi:10.1016/S0749-6419(99)00059-5.

[8] J. (Jean) Lemaître, J.-L. Chaboche, Mechanics of solid materials, Cambridge University Press, 1990.

[9] S. Bari, T. Hassan, An advancement in cyclic plasticity modeling for multiaxial ratcheting simulation, Int. J. Plast. 18 (2002) 873-894. doi:10.1016/S0749-6419(01)00012-2.

[10] M. Franulović, R. Basan, I. Prebil, Genetic algorithm in material model parameters' identification for low-cycle fatigue, Comput. Mater. Sci. 45 (2009) 505-510. doi:10.1016/j.commatsci.2008.11.012.

[11] M. Franulović, R. Basan, R. Kunc, I. Prebil, Automation of LCF material model parameters' identification, Comput. Mater. Sci. 48 (2010). doi:10.1016/j.commatsci.2010.02.019.

[12] M. Franulović, B. Križan, R. Basan, Residual Stresses in Gear Tooth Root, in: Proc. 3rd Int. Conf. Power Transm. '09, 2009: pp. 279-284.

[13] M. Franulović, R. Basan, R. Kunc, I. Prebil, Numerical modeling of life prediction of gears, in: Procedia Eng., 2011. doi:10.1016/j.proeng.2011.04.094.

[14] M. Franulović, B. Križan, R. Basan, Simulating elastic-plastic material response of gear's tooth root, in: 15th Int. Conf. Mach. Des. Prod., 2012. 